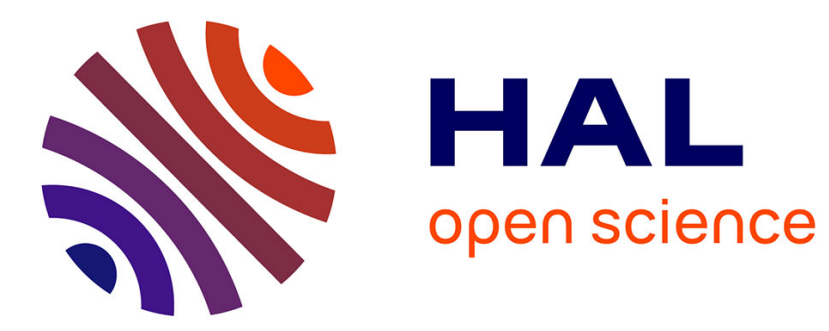

\title{
Degradation of epoxy coatings under gamma irradiation
} Fatma Djouani, Yahya Zahra, Bruno Fayolle, M Kuntz, Jacques Verdu

\section{To cite this version:}

Fatma Djouani, Yahya Zahra, Bruno Fayolle, M Kuntz, Jacques Verdu. Degradation of epoxy coatings under gamma irradiation. Radiation Physics and Chemistry, 2014, 82 (1), pp.54-62. 10.1016/j.radphyschem.2012.09.008 . hal-00980787

\section{HAL Id: hal-00980787 https://hal.science/hal-00980787}

Submitted on 7 May 2014

HAL is a multi-disciplinary open access archive for the deposit and dissemination of scientific research documents, whether they are published or not. The documents may come from teaching and research institutions in France or abroad, or from public or private research centers.
L'archive ouverte pluridisciplinaire HAL, est destinée au dépôt et à la diffusion de documents scientifiques de niveau recherche, publiés ou non, émanant des établissements d'enseignement et de recherche français ou étrangers, des laboratoires publics ou privés. 


\title{
Degradation of epoxy coatings under gamma irradiation
}

\author{
F. Djouani ${ }^{\text {a }}$, Y. Zahra ${ }^{\text {a,b }}$, B. Fayolle ${ }^{\text {a,* }}$, M. Kuntz ${ }^{\text {b }}$, J. Verdu ${ }^{\text {a }}$ \\ a Laboratoire Procédé et Ingénierie en Mécanique et Matériaux (UMR8006), Arts et Metiers ParisTech, 151 Boulevard de l'Hôpital, 75013 Paris, France \\ ${ }^{\mathrm{b}}$ EDF RED, Département Matériaux et Mécanique des Composants, Avenue des Renardières, Ecuelles, 77250 Moret sur Loing, France
}

- The effects of irradiation at three distinct dose rates have been studied on two epoxy networks.

- DGEBA-polyamidoamine networks appear more stable than DGEBA-polyoxypropylene diamine ones.

- A simple kinetic model involving methyl ketones is proposed.

Keywords:

Epoxy

Radio oxidation

Kinetic model

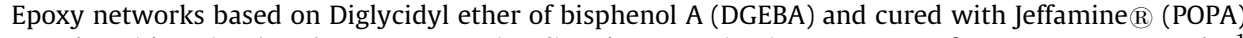
or polyamidoamine (PAA) were gamma irradiated at $25{ }^{\circ} \mathrm{C}$ in air. Dose rates of 50,200 or $2000 \mathrm{~Gy} \mathrm{~h}^{-1}$ for doses up $100 \mathrm{kGy}$ were used. Structural changes were monitored by IR spectrophotometry, DSC and sol-gel analysis.

Both networks display some common features: for $\mathrm{I} \geq 200 \mathrm{~Gy} \mathrm{~h}^{-1}$, reaction products grow proportionally to time and the rate is a decreasing function of dose rate. The simplest explanation is that peroxy radicals are the main precursors of these products (in the dose rate domain under study), through a unimolecular rearrangement of which an hypothetical mechanism is proposed. DGEBA-POPA are more reactive then DGEBA-PAA networks (according to IR criteria), that can be attributed to the high reactivity of tertiary $\mathrm{CH}$ bands in polyoxypropylene segments. The oxidation of these sites leads to methyl ketones. A simple kinetic model in which methyl ketones result from rearrangements of tertiary peroxyls and from tertiary alkoxyls was proposed. It leads to an expression of the radiochemical yield of methyl ketones $(\mathrm{G}(\mathrm{MK}))$ of the form

$G(\mathrm{MK})=a+b I^{-1 / 2}$

where $a$ and $b$ are parameters depending of elementary rate constants. Experimental $G(\mathrm{MK})$ values are reasonably well fitted by this equation. In DGEBA-PAA networks, a wide variety of oxidation products, among which amides predominate, can be observed. In these networks, chain scissions predominate over crosslinking, whereas a slight predominance of crosslinking was observed, at least for the lowest dose rate, in DGEBA-POPA.

\section{Introduction}

Epoxy networks of relatively low glass transition temperatures (typically $50{ }^{\circ} \mathrm{C} \leq T_{g} \leq 80^{\circ} \mathrm{C}$ ) are often used as coatings in nuclear industry applications. Recently considerable attention has been paid to the improvement of certain properties such as: scratch and abrasion resistance, tensile strength, impact resistance or heat stability. One approach involved the incorporation of nanoscopic fillers (Chazeau et al., 2004). These fillers are expected to play a positive chemical role by trapping radicals or degradation by-products and

\footnotetext{
* Corresponding author.

E-mail address: bruno.fayolle@ensam.eu (B. Fayolle).
}

hence decreasing the ageing rate. However, these fillers can also undergo degradation and generate undesirable by-products.

There is a wide range of chemical processes that can be induced by radiochemical or thermal oxidation. Chain scission and cross-linking are particularly important because, at moderate conversions, only the changes in crosslink density are capable of influencing the thermomechanical behavior. The quantitative determination of the number of chain scission and cross-linking events and their relationship with the elementary radical oxidation processes is thus of primary importance in understanding the overall mechanism.

Even taking into account the wide range of relevant structures, the recent literature on the radiochemical ageing of epoxy networks remains relatively scarce (Ngono-Ravache et al., 2001; 
Devanne et al., 2005; Ngono and Marechal, 2001; Vignoud et al., 2001; Longieras et al., 2006; Davenas et al., 2002; Crăciun et al., 2011). It seems reasonable to distinguish fully aromatic systems, essentially those used as composite matrices, from system-cured by aliphatic amines such as triethylene tetramine (Garcia et al., 2011; Benard et al., 2006, 2007), Jeffamine (Zaman et al., 2011), polyamidoamine (Astruc et al., 2009) or cycloaliphatic amines (Zhou et al., 2006). Among other possible applications, the latter can be used as coatings.

It is useful to summarize the published data as follows:

a) Nature of the monomers

The constitutive repeat unit (CRU) of an amine cross-linked epoxy polymer can be represented as follows:<smiles>CCC(O)COPCC(O)CC(O)CN(CC(O)CC)NN(C)C</smiles>

Here $\mathrm{E}$ is the diepoxide nucleus and $\mathrm{A}$ is the diamine nucleus. For example, in the case of PAA, the bisphenol $\mathrm{A}$ is the nucleus $\mathrm{E}$ and the aliphatic polyamide is the nucleus $\mathrm{A}$.

All these networks have in common the isopropanol segment (ip). This segment is, no doubt, a "weak point", as well in purely radiochemical processes as in radical oxidation ones.

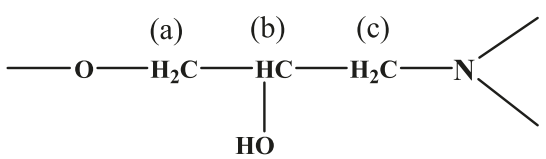

The three carbons ( $\mathrm{a}, \mathrm{b}$ and $\mathrm{c}$ ) are relatively susceptible to radical attack because they are linked to electronegative atoms ( $\mathrm{O}$ or $\mathrm{N})$ whose destabilizing effects are well known (Bellenger and Verdu, 1985). Oxidation of either carbon (a) or (b) is expected to lead to a wide range of products. Of these, the carbonylcontaining ones such as aldehydes, ketones, acids, peracids and others have their IR stretching bands in the $1710-1770 \mathrm{~cm}^{-1}$ range. Carbon (c) can give rise to several products among which is a tertiary amide. Although this is also a carbonyl compound, its IR stretching band can be easily distinguished from the preceding ones since it is found around $1660 \mathrm{~cm}^{-1}$. The presence of amides has been observed by practically all the authors who used IR spectrophotometry. They sometimes appear as the major oxidation products thus confirming that an important part of the oxidation events occur in the immediate vicinity of the tertiary amines which are in fact the nodes of networks.

In the case of coating systems, the diamine moiety A contains also carbons which have a relatively high reactivity to oxidation, for example carbon (d) in PAA and carbon (e) in POPA. diamine structure on stability? Is it possible to predict this influence?

b) Diffusion controlled oxidation

Since oxidation is diffusion controlled, it is clear that the totality of available oxygen is consumed in a superficial layer. In thick samples, the deep layers undergo only anaerobic radiochemical ageing whereas the superficial layers undergo oxidation. However, anaerobic reactions can have a positive effect on cross-link density changes (as discussed below). According to Audouin et al. (Girois et al., 1997; Richaud et al., 2010), the thickness of the oxidized layer (TOL) can be estimated using a scaling law:

$\mathrm{TOL} \approx\left(\frac{D}{K}\right)^{1 / 2}$

Here $D$ is the diffusion coefficient of oxygen in the polymer and $K$ is the pseudo first order rate constant of oxygen consumption and is defined by

$K=\left(\frac{r_{o x}}{C}\right)$

where $r_{o x}$ is the rate of oxygen consumption and $C$ is the oxygen concentration in the polymer.

The thickness of the oxidized layer is thus expected to depend on all the exposure parameters influencing $D$ and $K$. In particular, these are temperature, dose rate and oxygen partial pressure.

c) Changes in cross-link density

At reasonably low conversions, the radiochemical or oxidation reactions are expected to influence the thermomechanical properties only if they induce changes in the cross-link density. Such changes can result only from chain scissions or from cross-linking events.

If $v, s$ and $x$ are the numbers of elastically active chains, chain scissions and cross-linking events per mass unit, respectively, then at low conversions for a fully cured sample, the following relationship can be written (Galant et al., 2010):

$v=v_{0}-3 s+2 x$

Indeed, since chain scission and cross-linking have opposite effects, then a knowledge of $s$ and $x$ or at least $v$, is crucial for the understanding of the mechanical property changes. On the other hand, in view of kinetic modeling and lifetime prediction, it is also necessary to associate chain scission and cross-linking events to the elementary steps of the radiochemical ageing process.

d) Radiochemical vs thermochemical initiation

Let us consider the simplest case of oxidation in oxygen excess at constant initiation rate $r_{i}$. According to a very classical kinetic model, the whole oxidation rate $r_{o x}$ will be given by

$r_{o x}=k_{3}[P H]\left(\frac{r_{i}}{2 k_{6}}\right)^{1 / 2}$

Here $k_{3}$ and $k_{6}$ are the rate constants of propagation (III) and termination (VI) reactions, respectively. These reactions are the following:

(e)
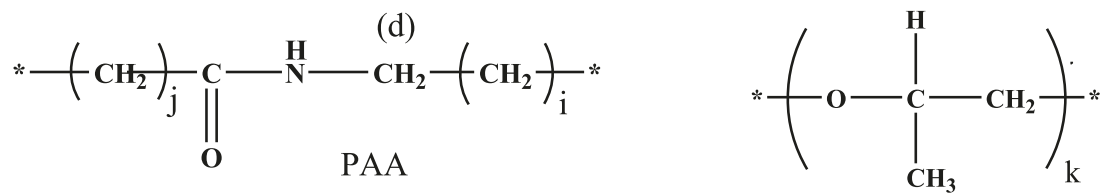

POPA

From a practical point of view, the important questions are: for a given epoxide such as DGEBA, what is the influence of the
(I) Initiation: Polymer $+\mathrm{O}_{2} \rightarrow$ radicals $\mathrm{POO}^{\circ}\left(r_{i}\right)$

(II) Propagation: $\mathrm{POO}^{\circ}+\mathrm{PH} \rightarrow \mathrm{POOH}+\mathrm{P}^{\circ}\left(k_{3}\right)$

(III) Termination: $\mathrm{POO}^{\circ}+\mathrm{POO}^{\circ} \rightarrow$ Inact. prod. $+\mathrm{O}_{2}\left(k_{6}\right)$ 
Initiation can be due to polymer radiolysis or hydroperoxide decomposition. This latter can be simply written

$\delta \mathrm{POOH} \rightarrow \alpha \mathrm{P}^{\circ}+\beta \mathrm{POO}^{\circ}$

Here $\alpha=2$ and $\beta=0$ for $\delta=1$ (unimolecular decomposition) and $\alpha=1$ and $\beta=1$ for $\delta=2$ (bimolecular decomposition).

One sees that initiation by hydroperoxyde decomposition becomes favored when hydroperoxides can accumulate in the polymer. Schematically $r_{i} \propto[\mathrm{POOH}]^{\delta}$.

In the absence of irradiation at moderate temperatures, initiation can result only from $\mathrm{POOH}$ decomposition. Oxidation is thus auto-accelerated and can display an induction period.

Propagation is relatively slow. Structure-reactivity relationships are well known and $k_{3} \sim 10^{-3} \pm 1{ }^{1} \mathrm{~mol}^{-1} \mathrm{~s}^{-1}$ for most common hydrocarbon substrates at $30^{\circ} \mathrm{C}$ (Korcek et al., 1972). Carbons having electronegative atoms in $\alpha$ position and tertiary carbons are among the most reactive ones.

Termination is also slow because it involves a bimolecular combination of rare species ( $\mathrm{POO}^{\circ}$ radicals). Such reactions are inevitably diffusion controlled in polymer matrices where molecular motions are relatively slow. In addition, for tertiary radicals, terminations are about one thousand times slower than for secondary or primary ones.

The combination of relatively fast propagation with a relatively slow termination can explain a high reactivity towards oxidation. Whereas radiochemical initiation is almost independent of temperature and its rate is proportional to dose rate, thermal initiation by $\mathrm{POOH}$ decomposition is dose rate independent but highly activated by a temperature increase. It is also sharply linked to $\mathrm{POOH}$ concentration. So that the domain of predominance of $\mathrm{POOH}$ decomposition in radical chain initiation, in a time-temperature space, is expected to have the shape of Fig. 1.

A kinetic model corresponding to this situation has been already published (Khelidj et al., 2006). Finally, the current research work in this domain is aimed to at clarifying the position

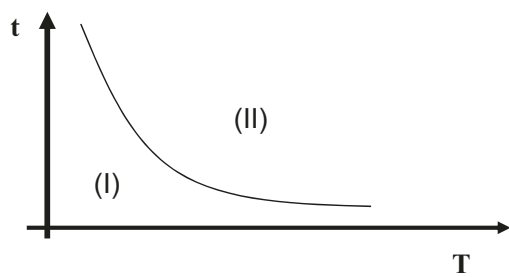

Fig. 1. Schematization of the stability domain of $\mathrm{POOH}$ groups in the timetemperature space; hydroperoxides are stable in domain (I) of the system (material-exposure conditions) within a set of alternatives.

- Stability of isopropanol segment vs stability of diamine moiety.

- Importance of pure radiochemical reactions vs oxidation reactions.

- Crosslinking vs chain scission.

- Thermal initiation vs radiochemical initiation.

With this aim, a study involving two types of epoxy networks will be presented here namely DGEBA-PAA and DGEBA-POPA.

\section{Experimental}

\subsection{Materials}

The DGEBA used in this study has a number average molar mass of about $1170 \mathrm{~g} \mathrm{~mol}^{-1}$ which corresponds to a number average degree of polymerization of $n=3$ (see Fig. 2). The PAA has a number average degree of polymerization of $j=3.9$ whereas POPA shows a number average degree of polymerization of $1<x<3$.

Considering that the epoxides and amines are close to their stoichiometric ratio and that the cure conversion is close to unity, one can therefore estimate the crosslink density as being equal to $0.8 \mathrm{~mol} \mathrm{~kg}^{-1}$. Hence, the smallest constitutive repeat unit (CRU) of the networks would have the structure shown in Fig. 3. Cast films of $100-200 \mu \mathrm{m}$ thickness were used throughout this study.

\subsection{Irradiation conditions}

Irradiation by ${ }^{60} \mathrm{Co}$ gamma rays was performed using the irradiation facility "Brigitte" (SCKEN, Belgium) at $25{ }^{\circ} \mathrm{C}$ in air with dose rates of 50,200 or $2000 \mathrm{~Gy} \mathrm{~h}^{-1}$ and using 6 doses in the range $10-100 \mathrm{kGy}$.

\subsection{Characterization}

FTIR measurements were carried out using a Bruker IFS 28 spectrophotometer equipped with an ATR accessory. The spectra were recorded between 4000 and $600 \mathrm{~cm}^{-1}$; 64 scans were averaged for a resolution of $4 \mathrm{~cm}^{-1}$. The height of the peaks is determined from the baseline $\left(1810-1540 \mathrm{~cm}^{-1}\right)$. The concentration of a given species was tentatively estimated using the following equation:

$[$ Species $]=\frac{\varepsilon_{A r}[A r]}{\varepsilon_{\text {Species }}} \frac{A(\text { Species })}{A(A r)}$

where $A$ (species) and $\varepsilon$ species are the peak absorbance and molar absorptivity of the species under study, respectively. The terms $A(A r)$

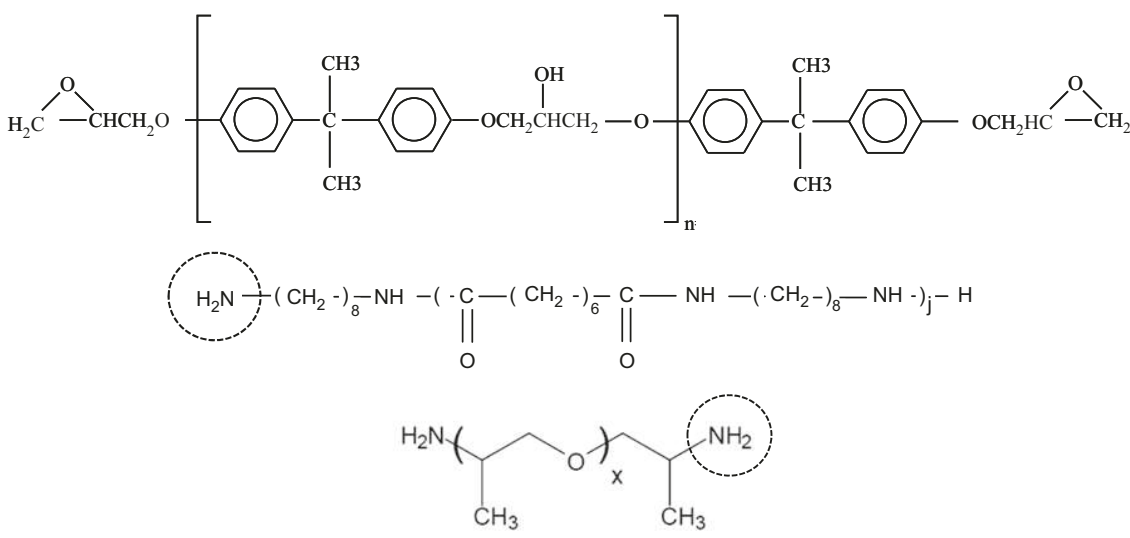

Fig. 2. Chemical structures of (i) DGEBA, (ii) polyamidoamine (PAA) and (iii) Jeffamine (POPA). 

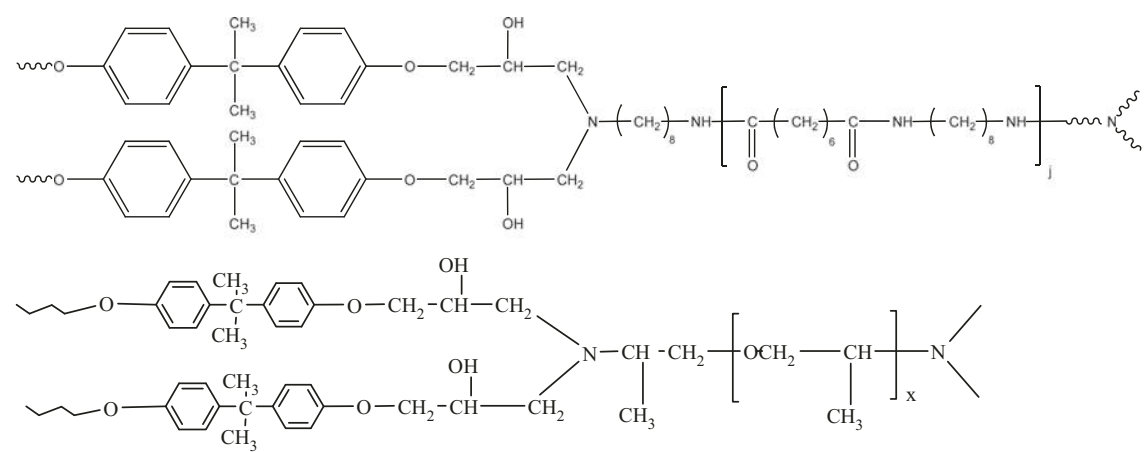

Fig. 3. Chemical structure of the networks studied.
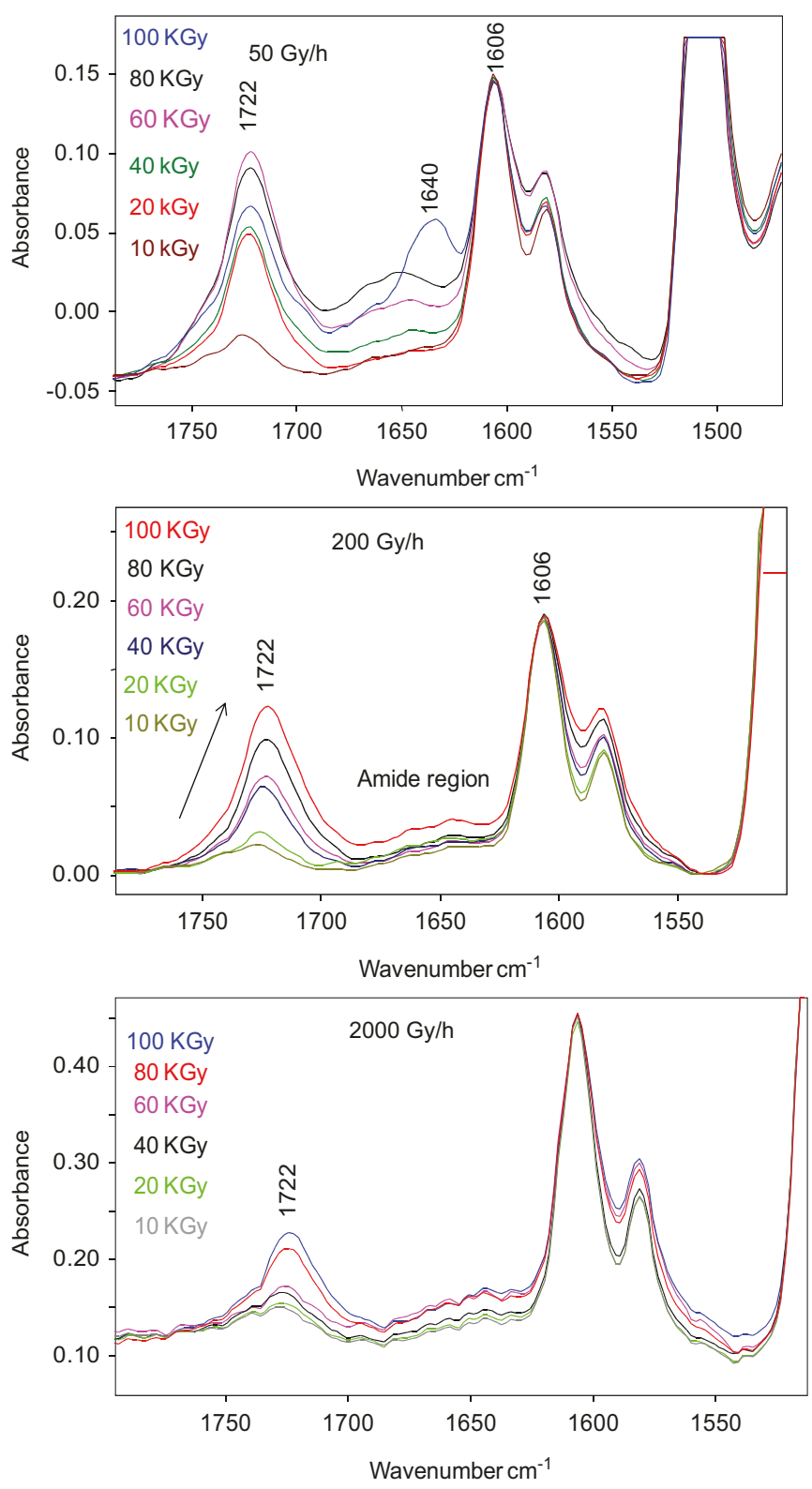

Fig. 4. FTIR spectra of epoxy/POPA during radiochemical ageing normalized at $1606 \mathrm{~cm}^{-1}$ for 50,200 and $2000 \mathrm{~Gy} / \mathrm{h}$ doses rates.

and $\varepsilon_{A r}$, are the peak absorbance and molar absorptivity of the species used as internal standards, respectively. The choice here was to use the aromatic peak at $1606 \mathrm{~cm}^{-1}$ as the internal standard: $\varepsilon$ species was taken as equal to $4701 \mathrm{~mol}^{-1} \mathrm{~cm}^{-1}$ for amides and $5001 \mathrm{~mol}^{-1} \mathrm{~cm}^{-1}$ for carbonyls (Bellenger and Verdu, 1986).

DSC measurements were carried out using a Q1000 modulated differential scanning calorimeter (from TA instruments) under a nitrogen flow rate of $50 \mathrm{ml} \mathrm{min}{ }^{-1}$. A temperature ramp was applied to the sample from 0 to $170{ }^{\circ} \mathrm{C}$ at a heating rate of $2{ }^{\circ} \mathrm{Cmin}^{-1}$.

A temperature modulation (amplitude $0.318^{\circ} \mathrm{C}$, period $60 \mathrm{~s}$ ) was superimposed on the ramp, thus making it possible to distinguish between reversible and irreversible processes.

Sol-gel analysis was performed using soxhlet extraction with THF as the solvent. After $24 \mathrm{~h}$ extraction, the samples were dried and weighed $\left(m_{f}\right)$. The soluble fraction $\left(w_{s}\right)$ was calculated by using

$w_{s}=\frac{m_{i}-m_{f}}{m_{i}}$

where $m_{i}$ is the initial mass of the sample.

\section{Results}

\subsection{Effect of irradiation on the DGEBA-POPA networks.}

Analysis of the IR spectra in the carbonyl stretching region (see Fig. 4) mainly reveals the growth of a quasi symmetric, relatively sharp peak at $1722 \mathrm{~cm}^{-1}$, which can be tentatively attributed to a methyl ketone (MK).

At high dose rates (200 and $2000 \mathrm{~Gy} \mathrm{~h}^{-1}$ ), no other species appears in this spectral range according to Fig. 4 . At the lowest dose rate $\left(50 \mathrm{~Gy} \mathrm{~h}^{-1}\right)$, another species appears at $1640 \mathrm{~cm}^{-1}$. Its growth is strongly auto-accelerated after $\sim 60 \mathrm{kGy}$ of exposure. This peak can be attributed to a tertiary amide (AM).

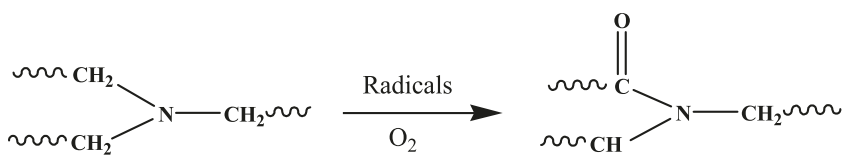

Peak intensities were translated into concentration values and these latter were plotted against the dose in Fig. 5. These curves can be analyzed in the following manner: for doses up to $\sim 60 \mathrm{kGy}$, the concentrations increase almost linearly with the dose, i.e. with time. Within this dose range, the amide yield is seen to be considerably lower than the ketone yield. This latter is a decreasing function of the dose rate. At doses higher than $60 \mathrm{kGy}$, the results clearly show that the amide yield increases abruptly while the ketone yield decreases. Hence, it is tempting to suggest that amides are formed at the expense of the ketones.

Significant changes are also observed in the $800-1000 \mathrm{~cm}^{-1}$ spectral range (Fig. 6): the two peaks, at 914 and $866 \mathrm{~cm}^{-1}$ progressively disappear. The peak at $914 \mathrm{~cm}^{-1}$ is usually 

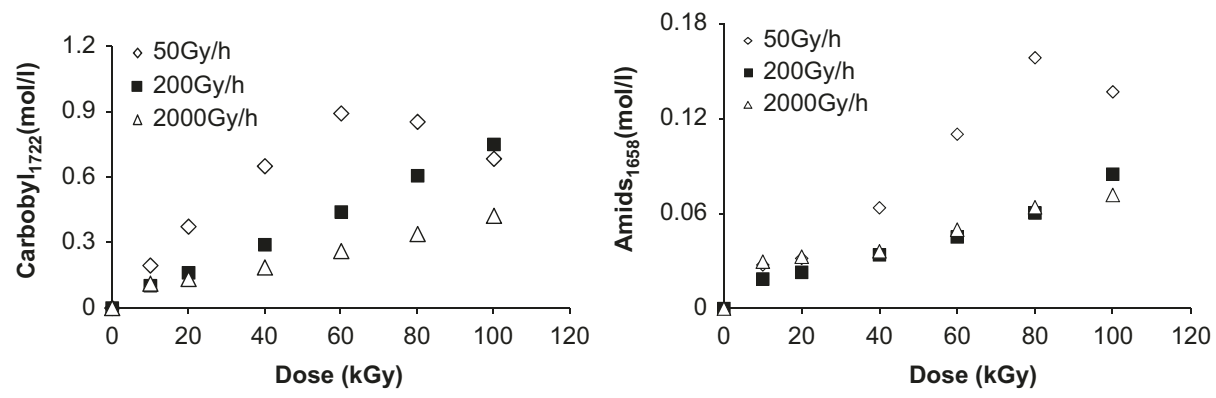

Fig. 5. Carbonyl and amid concentration against absorbed dose for DGEBA-POPA networks.

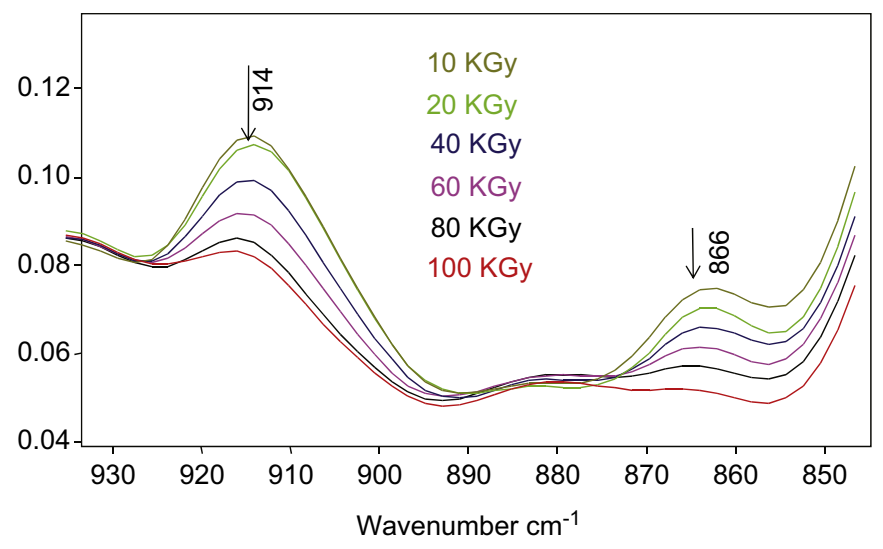

Fig. 6. Changes in IR spectra for DGEBA-POPA networks irradiated at $200 \mathrm{~Gy} \mathrm{~h}^{-1}$ dose rate.

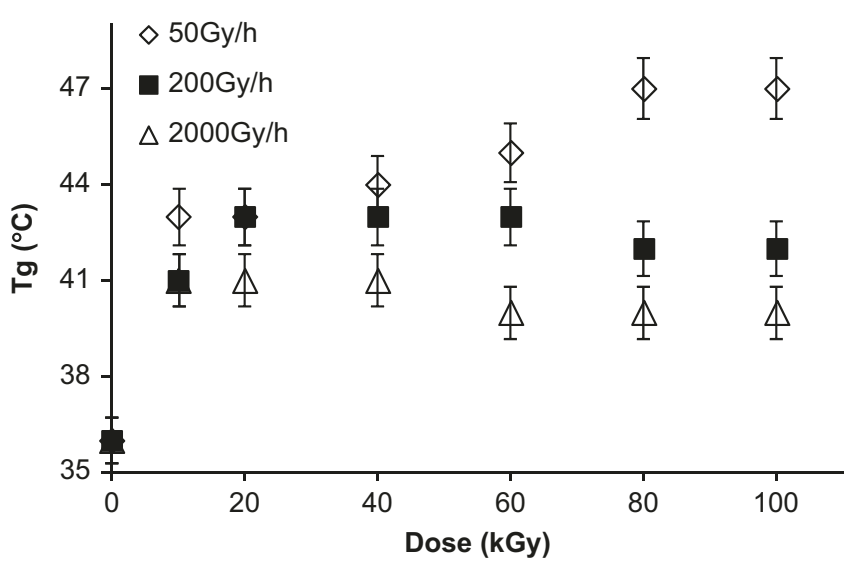

Fig. 7. $T_{g}$ changes against dose for DGEBA-POPA networks.

attributed to unreacted epoxides (EP). The peak at $866 \mathrm{~cm}^{-1}$ cannot be unambiguously identified.

DSC thermograms were used to determine the glass transition temperature $T_{\mathrm{g}}$. Its value has been plotted against in Fig. 7. It was found that $T_{g}$ increases for all dose rates of $4-6{ }^{\circ} \mathrm{C}$ in the first hours of exposure. Then at the highest dose rates (200 and $2000 \mathrm{~Gy} \mathrm{~h}^{-1}$ ) it remains almost constant whereas it continues to increase at the lowest dose rate $\left(50 \mathrm{~Gy} \mathrm{~h}^{-1}\right)$. This behavior is usually interpreted as follows: The fast initial increase can be attributed to post-cure. For the lowest dose rate, there is an additional cross-linking process occurring.

Sol-gel analysis could be expected to bring complementary data about cross-linking and chain scission processes. The changes of sol fraction are presented in Fig. 8. No change was observed in samples exposed at 200 and $2000 \mathrm{~Gy} \mathrm{~h}^{-1}$ dose rates. For the sample exposed to the lowest dose rate $\left(50 \mathrm{~Gy} \mathrm{~h}^{-1}\right)$, the

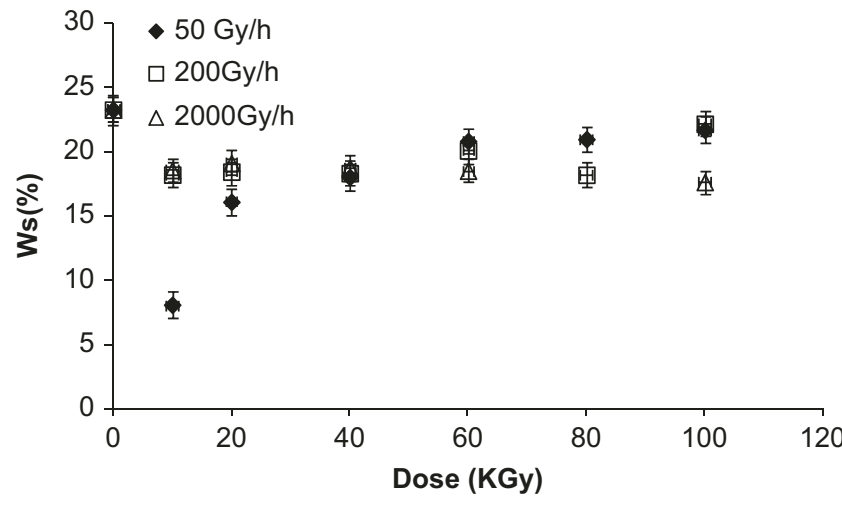

Fig. 8. Sol fraction against irradiation dose for DGEBA-POPA networks.

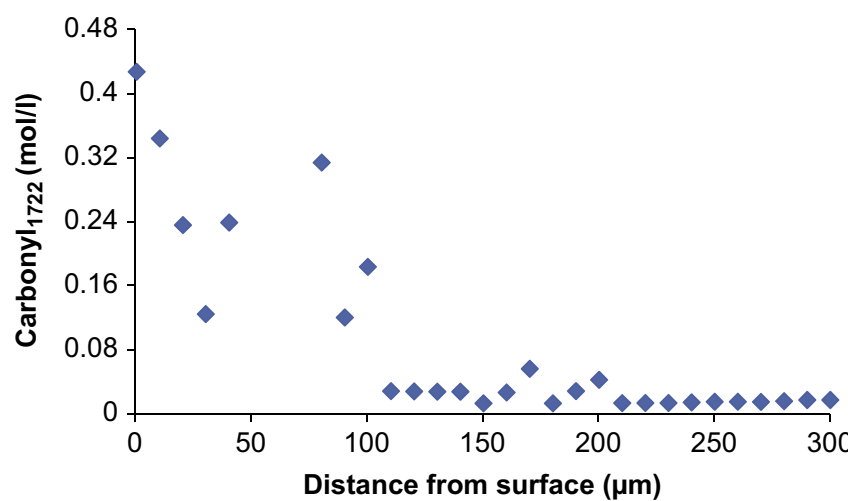

Fig. 9. Depth distribution of carbonyl concentration in epoxy (DGEBA-POPA) bulk sample irradiated at $2000 \mathrm{~Gy} \mathrm{~h}^{-1}$ dose rate.

sol fraction increases, and this is usually interpreted as predominant chain scission.

The fact that DSC and sol-gel results gave contradictory results could be attributed to sample heterogeneity. IR micro-spectrophotometry was used to check any eventual non-uniformity due to oxygen diffusion control. The thickness profile of the carbonyl concentration is presented in Fig. 9 for the sample exposed at $2000 \mathrm{~Gy} \mathrm{~h}^{-1}$ at a dose of $100 \mathrm{kGy}$. It can be clearly seen that the sample is effectively non-uniform; it displays an oxidized thin skinlike outer layer $90 \mu \mathrm{m}$ thick and a non-oxidized core.

\subsection{Effect of irradiation on the DGEBA-PAA networks}

The IR spectra of irradiated DGEBA-PAA samples are shown in Fig. 10. At high dose rates (200 and $2000 \mathrm{~Gy} \mathrm{~h}^{-1}$ ), there is no change evident (Fig. 10 right side). It can be deduced by comparison that the changes which occur in the DGEBA-POPA samples at these dose rates are linked to structural modifications of the 

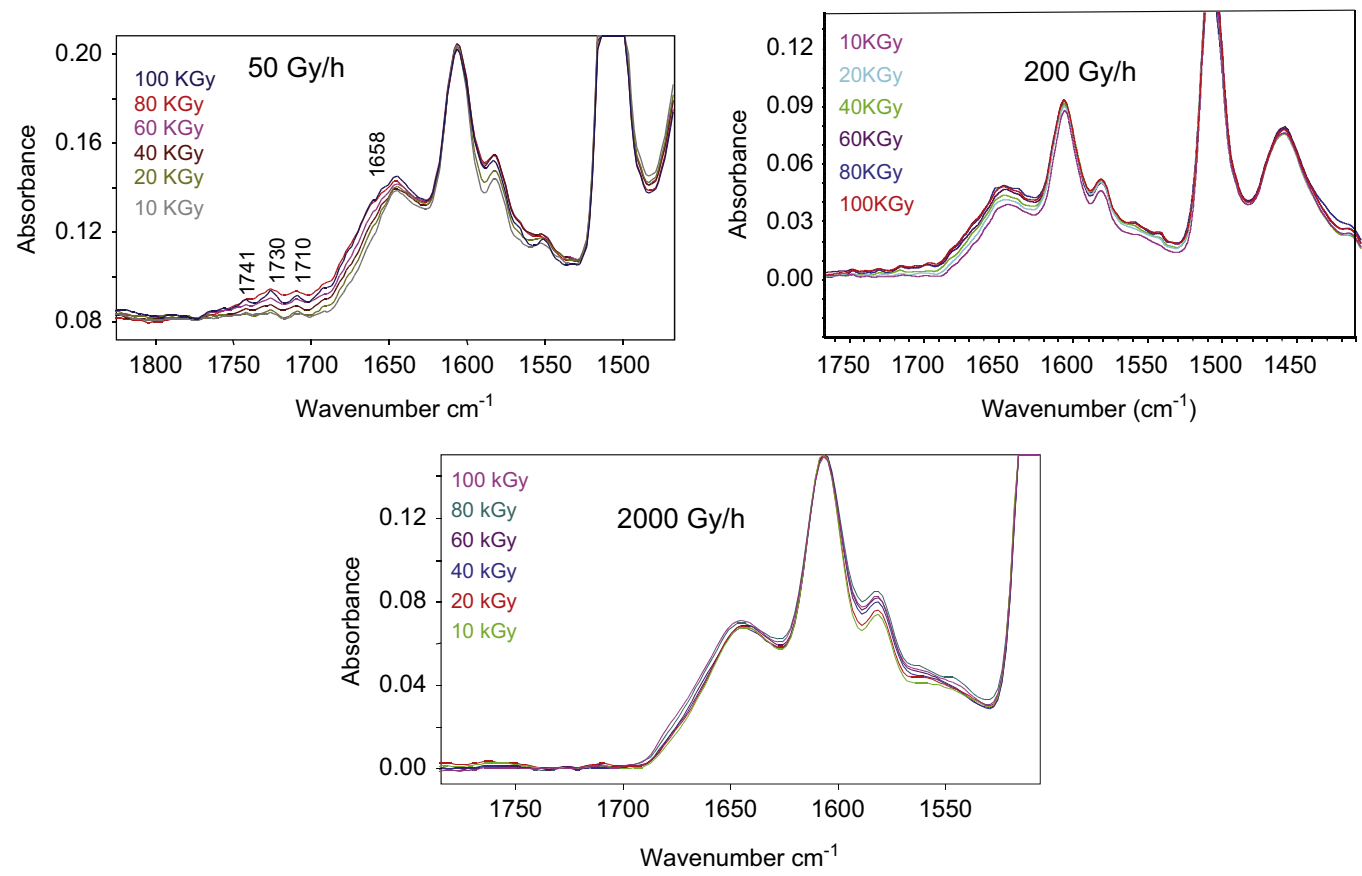

Fig. 10. FTIR spectra of DGEBA-PAA system during irradiation ageing at $25{ }^{\circ} \mathrm{C}$ to an absorbed dose rate of 50,200 and $2000 \mathrm{~Gy} \mathrm{~h}^{-1}$.

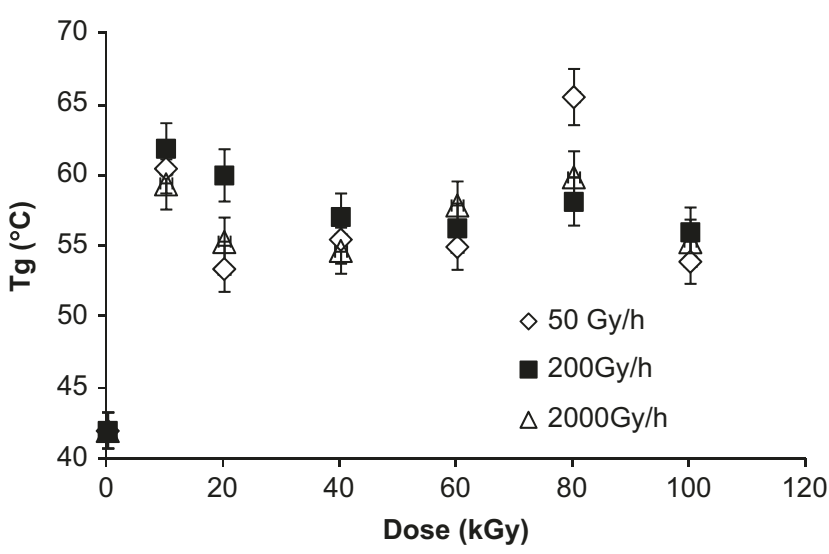

Fig. 11. $T_{g}$ changes against dose for DGEBA-PAA system.

POPA moiety. However, at $50 \mathrm{~Gy} \mathrm{~h}^{-1}$, changes are observed in DGEBA-PAA (Fig. 10 left side). Several small peaks appear in the carbonyl $\left(1710,1730\right.$ and $\left.1741 \mathrm{~cm}^{-1}\right)$ and in the amide region (1640-1680 $\mathrm{cm}^{-1}$ ) with a maximum close to $1658 \mathrm{~cm}^{-1}$. $T_{g}$ values, as assessed by DSC, were found to decrease in all cases (Fig. 11). Sol-gel analysis revealed that the sol fraction was almost constant at high dose rates while it increased significantly at the lowest dose rate (Fig. 12). Here, there is no obvious inconsistency between the DSC and sol-gel analysis results: a trend towards predominant chain scission is observed in both cases.

\section{Discussion}

\subsection{DGEBA-POPA networks}

In the DGEBA-POPA networks, the peak at $1722 \mathrm{~cm}^{-1}$, has been attributed to a methyl ketone (MK). Other studies also

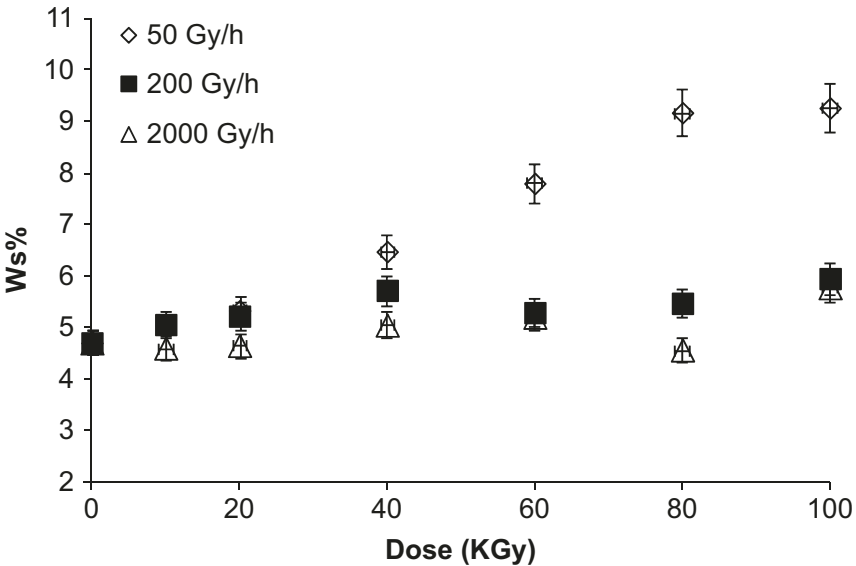

Fig. 12. Soluble fraction against dose for DGEBA-PAA system.

detected formation of $\mathrm{MK}$ in epoxy/amine systems by $\mathrm{C}-\mathrm{O}$ or $\mathrm{C}-\mathrm{N}$ scission. The high reactivity of POPA segments towards oxygen is well recognized. Nordling et al. (Nordling et al., 1965) showed almost one half century ago that polyoxypropylene is among the most oxidizable polymers. To identify mechanisms, we can start from three observations

a) MKs are not formed in the sample core, i.e. in the absence of oxygen

b) MKs are formed at constant rate in an initial period corresponding typically to $d \leq 60 \mathrm{kGy}$

c) The radiochemical yield of MKs, $(G(M K))$, is a decreasing function of dose rate.

According to structure reactivity relationships, the most important alkyl radicals, here, would be tertiary ones because they are more stable than secondary or primary ones. These radicals can react from propagation events, tertiary hydrogens being the most abstractable ones, or from rearrangement of secondary or primary radicals resulting directly from polymer 
radiolysis. These rearrangements can be intra or intermolecular hydrogen transfers, for instance by $1.2 \mathrm{H}$ migration.

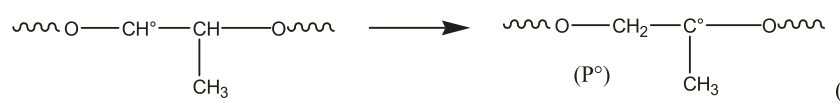

MKs could be tentatively attributed to rearrangement of $\mathrm{P}^{\circ}$ radicals by $\beta$ scission on oxygen side.

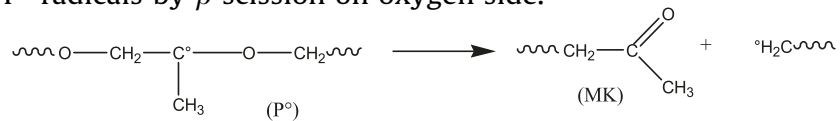

During irradiation, radicals $\mathrm{P}^{\circ}$ are formed in the whole sample volume. The fact that MKs are not formed in the sample core, where oxygen has not access, indicates that the above hypotheses can be set out. Since MKs are formed only in superficial layer, this is a proof that they result from a diffusion-controlled oxidation process (Fig. 9).

In the absence of oxygen, $\mathrm{P}^{\circ}$ radicals terminate neither by coupling (otherwise crosslinking would be observed) nor by disproportionation with themselves since they have not a hydrogen atom in $\alpha$ proton. There are two possibilities: they rearrange by $\beta$ scission in the carbon side or they undergo a disproportionation with secondary (or primary) radicals resulting from hydrolysis.
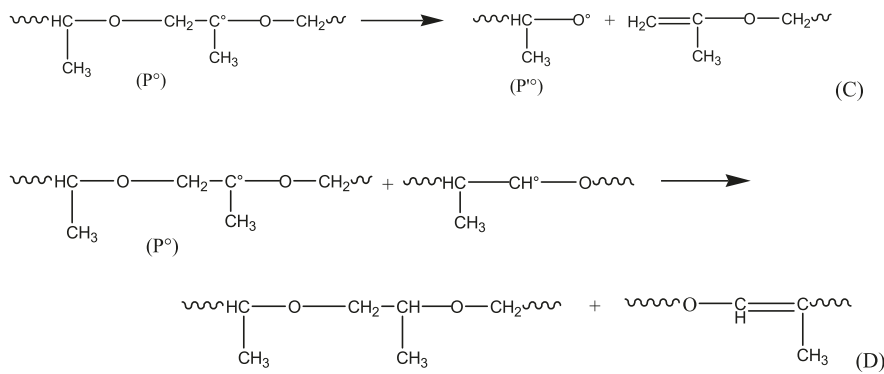

Both reactions lead to double bond formation. Double bands have a weak absorption in IR spectrum, which could explain why they are not observed. If mechanism (c) was predominating, chain scissions would occur in the core zone, which is not obvious. Furthermore, tertiary radicals $\left(\mathrm{P}^{\circ}\right)$ would probably partially disproportionate giving methyl ketones that would contradict experimental observations. The advantage of mechanism $(D)$ is that it is apparently compatible with all our experimental observations.

Let us return to the mechanism of methyl ketone formation. The fact that they are formed at constant rate, at least at doses $d \leq 60 \mathrm{kGy}$, can be simply explained as follows: in the exposure conditions under study, radical chain initiation can result only from two types of processes, polymer radiolysis and/or hydroperoxide decomposition.

Polymer $(\mathrm{PH})+\mathrm{h} v \rightarrow \mathrm{P}^{\circ} \quad\left(r_{i}=G I\right)$

$\delta \mathrm{POOH} \rightarrow \alpha \mathrm{P}^{\circ}+\beta \mathrm{PO}_{2}^{\circ} \quad\left(r_{i}=k_{i}[\mathrm{POOH}]^{\tilde{\sigma}}\right)$

In the first case (radiolysis), the initiation rate is constant and proportional to dose rate. In the second case (hydroperoxide decomposition), the initiation rate is more or less sharply linked to hydroperoxide concentrations, the reaction is thus autoaccelerated since hydroperoxides accumulate.

The fact that MKs are formed at a constant rate would be thus extremely difficult to explain if hydroperoxide decomposition played a significant role in radical chain initiation at low doses (indeed they accumulate and tend to become competitive at high doses, see below).

Since alkyl radicals and hydroperoxides have been eliminated as possible MK precursors, only two reactive species remain: peroxy $\left(\mathrm{POO}^{\circ}\right)$ and alkoxy $\left(\mathrm{PO}^{\circ}\right)$ radicals. Both hypotheses can be discussed on the basic of a simple model starting from the following hypotheses:

- Oxygen is in excess.

- Initiation results only from polymer radiolysis, hydroperoxide decomposition is negligible.

- According to the preceding hypothesis, alkoxy radicals can result only from non-terminating $\mathrm{POO}^{\circ}$ bimolecular combinations.

The simplest mechanistic scheme would thus involve 7 elementary reactions

Polymer $(\mathrm{PH})+\mathrm{hv} \circledast \mathrm{P}^{\circ} \quad\left(r_{i}\right)$

$\mathrm{P}^{\circ}+\mathrm{O}_{2} \rightarrow \mathrm{POO}^{\circ} \quad\left(k_{2}\right)$

$\mathrm{POO}^{\circ}+\mathrm{PH} \rightarrow \mathrm{POOH}+\mathrm{P}^{\circ}\left(k_{3}\right)$

$\mathrm{POO}^{\circ}+\mathrm{POO}^{\circ} \rightarrow$ inactive products $\left(k_{6}\right)$

$\mathrm{POO}^{\circ}+\mathrm{POO}^{\circ} \rightarrow 2 \mathrm{PO}^{\circ}+\mathrm{O}_{2} \quad\left(k_{7}\right)$

$\mathrm{PO}^{\circ} \rightarrow \mathrm{MK}+\mathrm{P}^{\circ} \quad\left(k_{8}\right)$

$\mathrm{POO}^{\circ} \rightarrow \mathrm{MK}+\mathrm{P}^{\circ}+$ products $\quad\left(k_{9}\right)$

The kinetic model can be composed of three differential equations $\mathrm{dP}^{\circ} / \mathrm{dt}=r_{i}-k_{2}\left[\mathrm{O}_{2}\right]\left[\mathrm{P}^{\circ}\right]+k_{3}[\mathrm{PH}]\left[\mathrm{POO}^{\circ}\right]+k_{8}\left[\mathrm{PO}^{\circ}\right]+k_{9}\left[\mathrm{POO}^{\circ}\right]$

$\mathrm{d}\left[\mathrm{POO}^{\circ}\right] / \mathrm{dt}=k_{2}\left[\mathrm{O}_{2}\right]\left[\mathrm{P}^{\circ}\right]-k_{3}[\mathrm{PH}]\left[\mathrm{POO}^{\circ}\right]$

$$
-2 k_{6}\left[\mathrm{POO}^{\circ}\right]^{2}-2 k_{7}\left[\mathrm{POO}^{\circ}\right]^{2}-k_{9}\left[\mathrm{POO}^{\circ}\right]
$$

$\mathrm{d}\left[\mathrm{PO}^{\circ}\right] / \mathrm{dt}=2 k_{7}\left[\mathrm{POO}^{\circ}\right]^{2}-k_{8}\left[\mathrm{PO}^{\circ}\right]$

The stationary state hypothesis can be written

$\mathrm{d}\left(\mathrm{P}^{\circ}\right) / \mathrm{dt}+\mathrm{d}\left(\mathrm{POO}^{\circ}\right) / \mathrm{dt}+\mathrm{d}\left(\mathrm{PO}^{\circ}\right) / \mathrm{dt}=0 r_{i}-2 k_{6}\left[\mathrm{POO}^{\circ}\right]^{2}=0$

so that

$\left[\mathrm{POO}^{\circ}\right]=\left(r_{i} / 2 k_{6}\right)^{1 / 2}$

And, since $\mathrm{d}\left[\mathrm{PO}^{\circ}\right] / \mathrm{dt}=0$

$\left[\mathrm{PO}^{\circ}\right]=r_{i} k_{7} / k_{6} k_{8}$

And

$d[\mathrm{MK}] / \mathrm{dt}=r_{i} k_{7} / k_{6}+k_{9}\left(r_{i} / 2 k_{6}\right)^{1 / 2}$

If $G_{i}$ is the radiochemical yield for radical formation, $r_{i}=G_{i} I$

$$
\begin{aligned}
G(\mathrm{MK}) & =\frac{d[\mathrm{MK}]}{\mathrm{dt}} / \frac{\mathrm{dd}}{\mathrm{dt}}=\frac{1}{I} \frac{d[\mathrm{MK}]}{\mathrm{dt}} \\
& =G_{i} k_{7} / k_{6}+k_{9}\left(G_{i} / 2 k_{6}\right)^{1 / 2} I^{-1 / 2}=a+b I^{-1 / 2}
\end{aligned}
$$

here $a$ and $b$ are parameters independent of dose rate.

Let us notice that if MK resulted only from rearrangement of $\mathrm{PO}^{\circ}$ radicals, one would have $k_{9}=0$ and $G(\mathrm{MK})=a$, independent of dose rate. The fact that $G(\mathrm{MK})$ is a decreasing function of dose rate indicates that $k_{9} \neq 0$ and that peroxy radicals are also MK

Table 1

Dose rate $(I)$, reciprocal of the square root of dose rate, experimental value of the radiochemical yield of methyl ketones $G(\mathrm{MK})_{\exp }$, calculated value of $G(\mathrm{MK})_{\text {th }}$ using Eq. (15).

\begin{tabular}{llll}
\hline$I\left(\mathrm{~Gy} \mathrm{~s}^{-1}\right)$ & $\begin{array}{l}I^{-1 / 2} \\
\left(\mathrm{~Gy} \mathrm{~s}^{-1}\right)\end{array}$ & $\begin{array}{l}G(\mathrm{MK})_{\exp } 10^{6} \\
\left(\mathrm{~mol} \mathrm{l}^{-1} \mathrm{~Gy}^{-1}\right)\end{array}$ & $\begin{array}{l}G(\mathrm{MK})_{\mathrm{th}} 10^{6} \\
\left(\mathrm{~mol} \mathrm{l}^{-1} \mathrm{~Gy}^{-1}\right)\end{array}$ \\
\hline $1.389 \times 10^{-2}$ & 8.482 & 18.5 & 17.7 \\
$5.556 \times 10^{-2}$ & 4.243 & 7.8 & 9.1 \\
$55.556 \times 10^{-2}$ & 1.3416 & 4.4 & 3.2 \\
\hline
\end{tabular}


precursors through an unimolecular process of which the mechanism remains to establish.

Experimental values of $G(\mathrm{MK})$ have been reported in Table 1. A linear regression gave

$G(\mathrm{MK})=\left(0.454+2.029 I^{-1 / 2}\right) 10^{-6}$

$G(\mathrm{MK})_{\text {th }}$ values calculated with Eq. (15) were also listed in Table 1. According to this equation, MK formation from alkoxy radicals (a) would predominate over MK formation from peroxy radicals $\left(b I^{-1 / 2}\right)$ only at dose rates: $I>20 \mathrm{~Gy} \mathrm{~s}^{-1}$, i.e at least 36 times higher than the highest dose rate studied here. Two possible reasons can be invoked for this result:

a) The low yield of non-terminating $\mathrm{POO}^{\circ}$ combination, i.e. the low value of the ratio $k_{7} / k_{6}$.

Let us recall that $\mathrm{POO}^{\circ}$ combinations lead first to a tetroxide which decomposes rapidly to give a pair of $\mathrm{PO}^{\circ}$ caged radicals. These latter can deactivate mutually into the cage, giving a termination event, or escape from the cage. The relatively low value of a $\left(0.454 \times 10^{-6} \mathrm{~mol}^{-1} \mathrm{~Gy}^{-1}\right)$ could indicate that only a small fraction of $\mathrm{PO}^{\circ}$ radicals escape from the cage at the temperature under study. In other words, $\mathrm{POO}^{\circ}+\mathrm{POO}^{\circ}$ terminations are especially efficient.

b) The relatively high kinetic chain length $\ell$, let us recall that, in the absence of $\mathrm{POOH}$ decomposition, the kinetic chain length is given by the ratio between propagation rate $\left(k_{3}[\mathrm{PH}]\right)$ versus termination rate $\left(k_{6}\left[\mathrm{POO}^{\circ}\right]\right)$. By combining with Eq. (11), the kinetic chain length $\ell$ could be written:

$\ell=k_{3}[\mathrm{PH}] /\left(2 r_{i} k_{6}\right)^{1 / 2}$

knowing $r_{i}=G_{i} I$, Eq. 16 becomes

$\ell=k_{3}[\mathrm{PH}] /\left(2 G k_{6}\right)^{1 / 2} I^{-1 / 2}$

As a result, the kinetic chain length is then a decreasing function of dose rate.

Here, in a first approximation, MKs resulting of $\mathrm{PO}^{\circ}$ rearrangement can be considered as termination by-products. MKs resulting from $\mathrm{POO}^{\circ}$ rearrangement can be considered as propagation by-products. The ratio $\left[\mathrm{MK}\left(\right.\right.$ from $\left.\mathrm{POO}^{\circ}\right) / \mathrm{MK}\left(\right.$ from $\left.\left.\mathrm{PO}^{\circ}\right)\right]$ is thus an increasing function of the kinetic chain length $\ell$ and hence a decreasing function of dose rate, as experimentally observed.

The MK formation from peroxy radicals could be tentatively attributed to intramolecular propagation as follow:

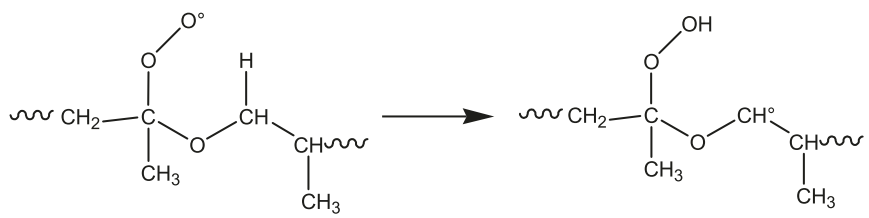

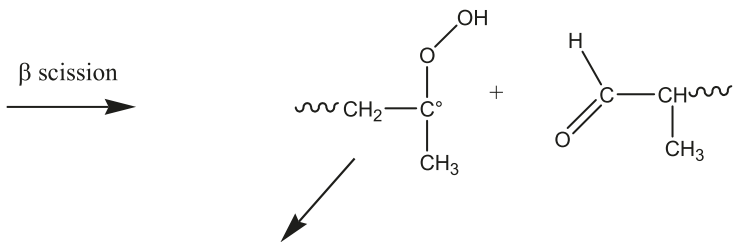

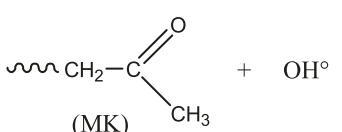

This intramolecular reaction is, indeed, in competition with intermolecular propagation; its yield is unknown at this state of our knowledge and the above hypothesis calls for an experimental checking, presumably on model compounds.
In DGEBA-POPA samples, amides growth rates are considerably slower than MK growth rates at high dose rates (200 and $\left.2000 \mathrm{Gyh}^{-1}\right)$ and initially at the lowest dose rate $\left(50 \mathrm{Gyh}^{-1}\right)$.

In other words, amides are formed with a yield considerably lower than methyl ketones in conditions where hydroperoxide decomposition is negligible.

At the lowest dose rate for doses typically higher than $20 \mathrm{kGy}$, amide growth is auto-accelerated. The result can be interpreted as follows: when radical chain initiation is predominant over polymer radiolysis, the radical attack is relatively selective and occurs mainly on tertiary carbons of polyoxypropylene chains. However, a small fraction of radicals can also attack $\alpha$ amino methylenes to give amides.

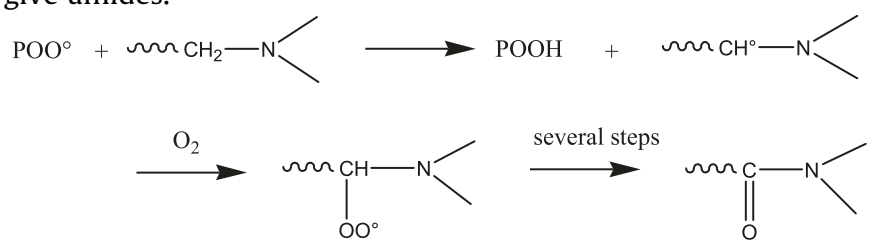

At low dose rates, however, the kinetic chain length is higher than at high dose rates (Eq. 16), hydroperoxides accumulate and thus decomposition becomes competitive. The radicals coming from this decomposition are apparently less selective and attack more efficiently $\alpha$ amino methylenes, giving thus a higher amide yield.

The existence, in virgin samples, of an IR peak at $914 \mathrm{~cm}^{-1}$ is presumably due to the presence of unreacted epoxide groups due to incomplete cure (Fig. 6). This peak disappears during exposure. The glass transition temperature $T_{g}$ increases rapidly at the beginning of irradiation ( $d \leq 20 \mathrm{kGy})$, that is consistent with the hypothesis of post-cure.

At high doses, $T_{g}$ changes depend on dose rate. At the lowest dose rate, $T_{g}$ continues to increase but at lower rate than initially, to approach $47^{\circ} \mathrm{C}$ at doses $\geq 80 \mathrm{kGy}$. At higher dose rates, $T_{g}$ reaches a maximum at c.a. $43^{\circ} \mathrm{C}$, for the dose rate of $200 \mathrm{Gyh}^{-1}$ and at c.a. $41^{\circ} \mathrm{C}$ for the highest dose rate $\left(2000 \mathrm{Gyh}^{-1}\right)$. Then a very slow decrease of $T_{g}$ can be suspected for both dose rates (Fig. 7);

The results of sol-gel analysis seem difficult to concily with preceding ones, except for the initial decrease of the sol fraction which can be also attributed to post-cure (Fig. 8). The sol fraction tends to stabilize around $18 \%$ for the highest dose rates 200 and $2000 \mathrm{Gyh}^{-1}$. In contrast, it increases slowly for the lowest dose rate, to reach about $22 \%$ at the dose rate of $100 \mathrm{kGy}$. Thus, $T_{g}$ measurements indicate predominant crosslinking while solgel analysis indicates slightly predominant chain scission. This discrepancy results probably from the samples heterogeneity linked to the skin-core structure of oxidized samples.

\subsection{The DGEBA-PAA network}

Let us now consider the DGEBA-PAA network. The absence of significant changes at the 200 and $2000 \mathrm{Gyh}^{-1}$ dose rates confirms the relative instability of the DGEBA-POPA system. It appears that the structural modifications seen previously in the latter system are mainly located on the polyoxypropylene segments. This apparent difference in stability must be considered with caution because of the different $T_{g} \mathrm{~S}$ values; $40-50{ }^{\circ} \mathrm{C}$ for DGEBA-POPA against $60-65{ }^{\circ} \mathrm{C}$ for DGEBA-PAA networks. During irradiation, DGEBA-PAA remains in glassy state but the DGEBAPOPAs are not far from their glass transition (this is the reason why they undergo post-cure). Thus they have a higher segmental mobility that can favor certain bimolecular chemical processes. A possible way to check an eventual effect of the mobility would be to compare DGEBA-POPA and DGEBA-PAA networks with the 
same glass transition temperatures; by modifying for instance the diamine length.

The fact that in DGEBA-PAA, structural modifications occur only at the lowest dose rate indicates that, presumably, these modifications result from hydroperoxide decomposition. It also shows that amides obey to a similar kinetic scheme as seen previously for MK, which means that they result from a process having a relatively long kinetic chain which leads to a predominance of the $I^{-1 / 2}$ term in the rate expression.

Except for the difference in global stability, already reported, the following differences with DGEBA-POPA can also be observed: the presence of several peaks in the carbonyl region indicates that there is a lower selectivity of radical attack. Tentative assignments are: acids $\left(1710 \mathrm{~cm}^{-1}\right)$; imides $\left(1730 \mathrm{~cm}^{-1}\right)$ and aldehydes $\left(1740 \mathrm{~cm}^{-1}\right)$. Acids are the result of aldehyde oxidation. Indeed, the aldehydic hydrogen can be readily abstracted and the resulting radical gives rise to a peracyl radical which evolves into peracids and acids. Aldehydes, as imides, can result from the attack of $\alpha$ amido methylenes in the polyamide chain.

Both aldehyde and acid groups result from chain scission. This process predominantes over crosslinking as evidenced by the decrease of $T_{g}$ (Fig. 11) and by increase of sol fraction (Fig. 12). These changes are considerably more marked in samples irradiated at the lowest dose rate than in the others. Here, one can make the same reasoning as for MK formation in DGEBA-POPA networks. Both $\mathrm{PO}^{\circ}$ and $\mathrm{POO}^{\circ}$ radicals can be the precursors of chain scissions by the above seen mechanism, reactions from $\mathrm{POO}^{\circ}$ radicals are formed at low dose rates as a result of kinetic chain length $(\ell)$ variation with dose rate.

\section{Conclusions}

The effects of gamma irradiation, in air at $25^{\circ} \mathrm{C}$, at three distinct dose rates, on two epoxy networks used as coatings have been studied. Both networks are based on the same diepoxide (DGEBA). They have similar crosslink densities $\left(\sim 1 \mathrm{~kg} \mathrm{~mol}^{-1}\right)$,

Their glass transition temperatures $T_{g}$ differ by about $20^{\circ} \mathrm{C}$. This difference can be important because in exposure conditions, one sample (DGEBA-POPA with $T_{g} \sim 43{ }^{\circ} \mathrm{C}$ ) is very close to its glass transition domain and presumably displays high segmental mobility while for DGEBA-PAA networks $\left(T_{g} \sim 65^{\circ} \mathrm{C}\right)$, irradiation was made in glassy state, at a greater distance from $T_{g}$.

The irradiation behavior of both networks displays some common features

a) At high dose rates (200 and $2000 \mathrm{Gyh}^{-1}$ ), the oxidation products grow at almost constant rate.

b) The yields of reaction products are decreasing functions of dose rate.

c) At the lowest dose rate $\left(50 \mathrm{Gyh}^{-1}\right)$, oxidation appears autoaccelerated, which can be attributed to the fact that hydroperoxide decomposition becomes a competitive initiation process.

Other features of the irradiation behavior are specific of the network structure.

In DGEBA-POPA networks, methyl ketones are the predominant reaction products, amides are formed at considerably lower rate. To explain the dose rate dependence of MK growth rates we suppose that MKs can be formed from two precursors: alkoxy $\left(\mathrm{PO}^{\circ}\right)$ and peroxy $\left(\mathrm{POO}^{\circ}\right)$ radicals of which the yield would be independent of dose rate $\left(\mathrm{PO}^{\circ}\right)$ and proportional to the reciprocal of the square root of dose rate $\left(\mathrm{POO}^{\circ}\right)$, the yield ratio being sharply linked to the kinetic chain length of radical chain oxidation. A simple kinetic model was elaborated; it predicts experimental results with a reasonable accuracy.

DGEBA-PAA networks appear intrinsically more stable than DGEBA-POPA ones, revealing that polyamide segments of PAA are less reactive than polyoxypropylene segments of POPA. From the practical point of view, however, the hierarchy of stabilities could be reversed. As a matter of fact, at low dose rate, DGEBA-POPA samples tend to crosslink while DGEBA-PAA undergoes chain scission of which the undesirable consequences of embrittlement will be expected.

\section{Refrences}

Astruc, A., Joliff, E., Chailan, J.-F., Aragon, E., Petter, C.O., Sampaio, C.H., 2009 Incorporation of kaolin fillers into an epoxy/polyamidoamine matrix for coatings. Prog. Org. Coat. 65, 158-168.

Benard, F., Campistron, I., Laguerre, A., Laval, F., 2006. Influence of silica fillers during the electron irradiations of DGEBA/TETA epoxy resins, part I: study of the chemical modification on model compounds. Polym. Degrad. Stab. 91, 2110-2118.

Benard, F., Campistron, I., Laguerre, A., Laval, F., 2007. Influence of silica fillers during the electron irradiation of DGEBA/TETA epoxy resins, part III: solidstate NMR investigations. Polym. Degrad. Stab. 91, 785-794.

Bellenger, V., Verdu, J., 1985. Oxidative skeleton breaking in epoxy-amine networks. J. Appl. Polym. Sci. 30, 363.

Bellenger, V., Verdu, J., 1986. Photo-oxidation of epoxy model compounds. Polym. Commun. 27, 279-281.

Chazeau, L., Gauthier, C., Vigier, G., Cavaille, J.Y., 2004. Handbook of OrganicInorganic Hybrid Materials and Nanocomposites, Pt2. In: Nalwa, H.S. (Ed.), American Scientific Publishers.

Crăciun, E., Zaharescu, T., Jitaru, I., Ignat, M., Cătănescu, I., Zărnescu, G., 2011 Radiation behavior of nanocomposite epoxy material. Univ. Politeh. Bucharest Sci. Bull. Series B 73, 75-86.

Devanne, T., Bry, A., Audouin, L., Verdu, J., 2005. Radiochemical ageing of an amine cured epoxy network. Part I: change of physical properties. Polymer 46 229-236.

Davenas, J., Stevenson, I., Celette, N., Cambon, S., Gardette, J.L., Rivaton, A., 2002. Stability of polymers under ionising radiation: the many faces of radiation interactions with polymers. Nucl. Instrum. Method B 191, 653-661.

Garcia, F.G., Leyva, M.E., Alencarde de Queiroz, A.A., Simõs, A.Z., 2011. Durability of adhesives based on different epoxy/aliphatic amine networks. Int. J. Adhes. Adhes. 13, 177-181.

Girois, S., Delprat, P., Audouin, L., Verdu, J., 1997. Oxidation thickness profiles during photooxidation of non-photostabilized polypropylene. Polym. Degrad. Stab. 56, 169-177.

Galant, C., Fayolle, B., Kuntz, M., Verdu, J., 2010. Thermal and radio-oxidation of epoxy coatings. Prog. Org. Coat. 69, 322-329.

Korcek, S., Chenier, J.H.B., Howard, J.A., Ingold, K.U., 1972. Can. J. Chem. 50 2285-2293.

Khelidj, N., Colin, X., Audouin, L., Verdu, J., Monchy-Leroy, C., Prunier, V., 2006 Oxidation of polyethylene under irradiation at low temperature and low dose rate. Part I. The case of pure radiochemical initiation. Polym. Degrad. Stab. 91, 1593-1597.

Longieras, N., Sebban, M., Palmas, P., Rivaton, A., Gardette, J.L., 2006. Multiscale approach to investigate the radiochemical degradation of epoxy resins under high-energy electron-beam irradiation. J. Polym. Sci. Part A: Polym. Chem. 44, 865-887.

Ngono-Ravache, Y., Foray, M.F., Bardet, M., 2001. High resolution solid-state $13 C$ NMR study of as-cured and irradiated epoxy resins. Polym. Adv. Technol. 12, 515-523.

Ngono, Y., Marechal, Y., 2001. Epoxy-amine reticulates observed by infrared spectrometry. III. Modifications of the structure an hydration abilities after irradiation in a humid atmosphere. J. Polym. Sci. Part B: Polym. Phys. 39, 1129-1136.

Nordling, P., Lee, T.L., Tobolsky, A.V., 1965. Rubber Chem. Technol. 38, 1198-1205.

Richaud, E., Ferreira, P., Audouin, L., Colin, X., Verdu, J., Monchy-Leroy, C., 2010 Radiochemical ageing of poly(ether ether ketone). Eur. Polym. J. 46, 731-743.

Vignoud, L., David, L., Sixou, B., Vigier, G., 2001. Influence of electron irradiation on the mobility and on the mechanical properties of DGEBA/TETA epoxy resins. Polymer 42, 4657-4665.

Zaman, I., Le, Q.-H., Kuan, H.-C., Kawashima, N., Luong, L., Gerson, A., Ma, J., 2011 Interface-tuned epoxy/clay nanocomposites. Polymer 52, 497-504.

Zhou, Y., Pervin, F., Rangari, Vijaya K., Jeelani, Shaik, 2006. Fabrication and evaluation of carbon nano fiber filled carbon/epoxy composite. Mater. Sci. Eng. A 426, 221-228. 